\title{
School Bullying Among Teen Students: Its Causes and Methods of Modification from Public School Teachers' Perspectives at Lewa Al Jamea Directorate of Education in Jordan
}

\author{
Anas Nawafleh ${ }^{1}$, Haya Hussein Al-Tarawneh ${ }^{1} \&$ Hussein Al-Tarawneh $^{2}$ \\ ${ }^{1}$ Al-Ain University, United Arab Emerates \\ ${ }^{2}$ Al-Ahliyya Amman University, Amman, Jordan \\ Correspondence: Anas Nawafleh. E-mail: anas1984010@yahoo.com
}

Received: April 12, 2021

doi:10.5539/ass.v17n5p51
Accepted: April 23, $2021 \quad$ Online Published: April 27, 2021

URL: https://doi.org/10.5539/ass.v17n5p51

\begin{abstract}
This study aims to identify school bullying among teen students, its causes, and modification methods from public schools' teachers in the University Directorate of Education, Jordan. The study sample consists of (2128) male and female teachers selected by the stratified random sampling method. Moreover, a descriptive survey approach has been utilized in this study. Results indicated that the means of bullying modification methods and their causes came at the medium level on the tool as a whole. There were statistically significant differences in the bullying modification scale and its causes attributed to the variable of gender and favored female participants. The results also indicated statistically significant differences on the bullying modification scale and its causes that are attributed to the variable of educational qualification in favor of higher studies, in addition to statistically significant differences on the bullying modification scale and its causes that are attributed to the variable of years of experience in favor of those with experience of more than ten (10) years.
\end{abstract}

Keywords: bullying, teen students, public schools teachers, abuse

\section{Introduction}

Interest in studying bullying stems from the destructive effects of this phenomenon (Smith, 2000) as it is a general phenomenon practiced by individuals with various forms and methods and emerges when the appropriate conditions are available (Abu-Addayyar, 2012). The problem of bullying became a serious problem in schools, especially in schoolyards, corridors, classrooms, departures, and others (Bidwell, 1997). So (Abu Ghazal, 2009). indicates that the bullying problem negatively affects the school environment and the students' personal, emotional, and behavioral development, and in the same vein (Alsoufi \& Almalikim, 2012). state that school bullying is a form of aggression that occurs when a child is continuously exposed to negative behavior that causes him/her pain. Bullying comes in various forms, such as physical, verbal, sexual, or social (Schuiz et al., 2012). Therefore, the causes of bullying and its treatment methods should be identified to stop this dangerous phenomenon, which leads to negative effects on students and their parents. Hence, it is vital to spread awareness among school principals, administrators, teachers, and parents regarding dealing with bullies and addressing this phenomenon to reduce its spread within the education sector.

\subsection{Implications of the Study}

The importance of current school study.

1 -Teachers and principals benefit by recognizing the reasons and ways of dealing with bullying.

2-Guidance, supervisors, and interested people benefit by preparing guiding programs to decrease the phenomena

3-It paves the way to increase researches to make them wider.

\subsection{Objectives of the Study}

This study leads to:

1-Recognizing the bullying phenomena among teenage students from the teacher's point of view. 
2-Recognizing the reasons for bullying among teenage students.

3-Providing recommendations which help to minimize the bullying phenomena among students.

\subsection{Statement of the Problem}

Causes of bullying stemmed from self and familial factors related to the student's school environment (Ghouli \& Al-I'kili, 2018). This phenomenon's negative effects differ at both the psychological and social levels for the bullying person. The victim, as the bullying, exhibits several psychological disorders characterized by aggressive behavior, anti-behavior against social values and traditions, poor social harmony, and adjustment (Albahhas, 2012). A study conducted by the National Center for Child Health and Human Resources Development indicated that more than one million American school students suffer from bullying, and more than 160,000 students run away from schools because of bullying (Bahshawi \& Hassan, 2015).

The researcher believes that the problem of school bullying is among the problems that cause psychological and physical harm for the bullied student, as the presence of bullying within school hinders the learning process among students and leads to psychological and physical harm, and creates issues and disturbances for both the bullied and his/her parents. Thus, the factors and causes for the occurrence of bullying behavior should be identified to stop its spread and reduce its risks within the school environment. The researcher also sees that bullying behavior has become a phenomenon that threatens school safety and affects students at all levels, including the psychological, social, and emotional aspects, so the causes and effects of this phenomenon should be addressed to stop its spread among teen students.

\subsection{Research Questions}

This study attempts to answer the following research questions:

1- What are the causes of school bullying from teachers' perspectives?

2- What are the methods of school bullying modification from teachers' perspectives?

3- Are there statistically significant differences at the value $(\alpha=0.05)$ in teachers' perspectives about bullying causes and modification methods based on the variables of gender, educational qualification, and years of experience?

\subsection{Limitations of the Study}

1-Subjective limits: Bullying phenomena among the school students.

2-Location: Government schools (capital state/ Amman).

3-People: teachers in the capital state schools

4-Timing: Second term 2019/2020

\subsection{Significance of the Study}

This study's significance lies in that it addresses school bullying among teen students and attempts to offer a source for excluding this dangerous phenomenon from schools. Moreover, it will represent a reference for researchers to expand the topic and address it about other variables and different age groups of students.

\section{Literature Review}

Bullying is a form of violence, abuse, and harm directed from a person or a group of people towards another person (Fikri \& Ali, 2015). (Stanford \& Schulz, 2002). emphasize that bullying is the frequent exposure of an individual to a negative behavior from one or more parties, and is intentional and causes harm for the victim (Alsobhiyeen \& Alqdah, 2015). and educational bodies should draw plans to limit the spread of the bullying phenomenon through increasing students' and parents' awareness regarding the concept of bullying, its causes, and how to address and treat it (Alyafi'I, 2018).

Bu-Nab (2017) states that among the causes of the behavior of students bullies are: 1- Familial causes: as a student who witnesses and sees violent acts at home tends to be more violent at school, 2- Personal causes: bullying may be due to feeling bored or the lack for awareness about its dangers to others or due to anxiety, unhappiness at home, or due to being a victim of bullying before, 3- Individual's psyche related causes: based on feelings, emotions, instincts, anxiety, stress, and frustration; and 4- School related causes: the various changes, the lack for clarity of instructions and systems, and the crowded classrooms, all of this stimulates the students' bullying behavior.

Of the methods that limit and reduce the bullying behavior phenomenon (Bilmahi, 2017). follows up the behaviors of hostiles and their victims at school and asks parents to observe their behaviors at home and during 
and after therapy. The school counselor also has a significant role in the therapy and in providing a safe familial environment and strengthening the relationship between the children and their parents by continuously providing support, discussion, and communication with children and by encouraging them to share their problems with their parents, besides, helping the bullied children to gain self-confidence at various life aspects, not forgetting the teachers' role in offering flexibility and non-authoritarian personality at the classroom.

\subsection{Early Studies}

Al-Omari (2019) investigated the school bullying problem among elementary-level students on a sample of 14 principals, 10 teachers, and 36 supervisors who were randomly selected, and the results indicated that school bullying among elementary-level students came at a high level, and the causes of school bullying among them came at a high level, too. Also, results indicated statistically significant differences for school bullying among elementary level students, preventing the problem of bullying and treating it. These differences are attributed to the variables of age and parents' job position.

The study of Lisa, De. Luce et al. (2019). investigated whether the correlation amongst teachers' (Such as efficiency, job satisfaction, and self-efficiency) limits school bullying. Results indicated that teachers' efficiency does limit school bullying and also reduces bullying among students.

Ken Rugb (2018) conducted a study to determine the aspects of teachers' belief in agreement or disagreement regarding the school bullying phenomenon. The sample included 451 Australian teachers. Results indicated the agreement of more than $75 \%$ of the responses on most of the questions. However, there were notable disagreements in other questions. Many teachers agreed the beliefs were different from the claims offered in the research. The difference in claims is attributed to the general knowledge and the source of information about bullying.

The study Gholi's (2018) aimed to identify the reasons for first intermediate grade students' bullying behavior and its modification methods from male and female teachers' perspectives on a random sample of 84 male and female teachers from Alrafidin Alrahmah intermediate schools. Results indicated various reasons for bullying, including self, familial, school environment, social environment, and media.

Aberrahim (2017) investigated high school principals' role in facing school bullying from teachers' perspectives at Alsharqeyyah governorate. The sample included (473) teachers from technical high schools. Results indicated a weak availability percentage for technical high school principals' role in facing school bullying from teachers' perspective.

The study of Bilmahi's (2017) addressed mitigation methods for teens' bullying from teachers' and supervisors' perspectives on a sample of (120) teachers and supervisors. Results indicated that among the most successful methods to mitigate bullying was to help students become self-independent, which increases self-confidence and helps to avoid teachers' blamed for the student in front of his/her peers, as well as creating a competitive spirit am students.

The study of Alqahtani (2015) aimed to identify the extent of awareness about bullying among elementary level female teachers and the procedures followed to prevent it within public schools in Riyadh city (Kingdom of Saudi Arabia) from their perspective. The study sample included (597) female teachers, and the results indicated their awareness of bullying and its forms and negative effects on the victims.

Alraqqad et al. (2017) studied the effect of school bullying on students' academic achievement from teachers' perspectives in Jordanian schools. The sample of the study included (200) teachers from West Amman region schools. Results indicated that the phenomenon of school bullying exists at all schools, whether public or private. Moreover, the phenomenon of school bullying affects students' academic achievement, whether victims or bullies.

Finally, Salhi et al. (2016) investigated the bullying behavior among students in Iran and teachers' and parents' perspectives in this regard. Four teachers and eight parents of bullies and victims were interviewed. Their view of the phenomenon is seen as a physical and verbal assault and somewhat associated with psychological factors, and they emphasized that the effect of religious beliefs should be taken into account in terms of bullying within the Iranian society due to parents' strictness with their children.

\subsection{Population and Sample of the Study}

According to the ministry of education, the study population included all public-school teachers in the University Directorate of Education in Amman, Jordan (2128 male and female teachers) during the first semester of the academic year 2019/2020 statics (2019/2020). 
A stratified random sample of (289) male and female teachers was selected from this population, representing approximately $13.58 \%$ of the original population of the study. The sample was selected based on the individuals' distribution within the original population according to the study variables using the Proportional Allocation for stratified random samples as shown in Table 1 below:

Table 1. Study population and sample distribution

\begin{tabular}{|c|c|c|c|c|c|c|c|}
\hline \multirow{3}{*}{ Gender } & \multirow{3}{*}{ Experience } & \multicolumn{4}{|c|}{ Educational Qualification } & \multicolumn{2}{|c|}{ Total } \\
\hline & & \multicolumn{2}{|c|}{ Bachelor } & \multicolumn{2}{|c|}{ Higher Studies } & \multirow[b]{2}{*}{ Number } & \multirow[b]{2}{*}{$\%$} \\
\hline & & Number & $\%$ & Number & $\%$ & & \\
\hline \multirow{4}{*}{ Males } & Less than 5 years & 21 & $7.3 \%$ & 5 & $1.7 \%$ & 26 & $9.0 \%$ \\
\hline & $5-10$ years & 24 & $8.3 \%$ & 5 & $1.7 \%$ & 29 & $10.0 \%$ \\
\hline & Above 10 years & 20 & $6.9 \%$ & 18 & $6.2 \%$ & 38 & $13.2 \%$ \\
\hline & Total & 65 & $22.5 \%$ & 28 & $\% 9.7$ & 93 & $\% 32.2$ \\
\hline \multirow{4}{*}{ Females } & Less than 5 years & 26 & $9.0 \%$ & 7 & $2.4 \%$ & 33 & $11.4 \%$ \\
\hline & $5-10$ years & 19 & $6.6 \%$ & 31 & $10.7 \%$ & 50 & $17.3 \%$ \\
\hline & Above 10 years & 65 & $22.5 \%$ & 48 & $16.6 \%$ & 113 & $39.1 \%$ \\
\hline & Total & 110 & $38.1 \%$ & 86 & $29.7 \%$ & 196 & $67.8 \%$ \\
\hline \multicolumn{2}{|r|}{ Total } & 175 & $60.6 \%$ & 114 & $39.4 \%$ & 289 & $100 \%$ \\
\hline
\end{tabular}

\section{Study Instruments}

After reviewing the related early literature and early studies such as Gholio AL-I'kili's (2018) study, the researcher developed the Bullying Behavior Modification Methods' Scale, and in its initial version, the tool consisted of (32) items. Also, the researcher developed the Bullying Causes Scale based on reviewing the theoretical literature and the early studies on the topic, such as Sahloul et al. (2018) study and consisted in its initial version of (18) items.

Instruments' Validity:

A- Content Validity for Both Instruments:

To verify the study instruments' face content validity, the researcher subscribed them to 10 faculty expert members specialized in psychological and educational counseling at faculties of education in Jordanian universities. This is for experts to offer their views on the accuracy and correctness of the tools in terms of clarity of items, linguistic formulation, appropriateness for assessing what they are supposed to assess, and items belonging to the dimension they listed within. Experts were asked to add and modify or exclude items as they see appropriate. Their opinions were taken into consideration, and some items were reformulated, and the items agreed upon by less than (80\%) of them were excluded. Thus, the tools in their final versions were the scale of bullying behavior modification methods consisted of (32) items and the scale of the bullying causes of (12) items.

\section{B- Instruments' Construct Validity:}

To verify the instruments' construct validity, both were applied on a pilot sample of (30) male and female teachers from the population of the study and other than its original sample to identify the internal consistency and the extent of the items' contribution by calculating the Pearson correlations for the items as a whole as shown in Table 2 below:

Table 2. Items correlation coefficients for the dimension score as a whole

\begin{tabular}{cccccccccc}
\hline Scale & Item no & correlation & Sig & Item no & correlation & Sig & Item no & correlation & Sig \\
\hline & 1 & $* 0.534$ & 0.000 & 12 & $0.544^{*}$ & 0.000 & 23 & $0.613^{*}$ & 0.000 \\
& 2 & $* 0.443$ & 0.000 & 13 & $0.660^{*}$ & 0.000 & 24 & $0.446^{*}$ & 0.000 \\
Bullying & 3 & $* 0.793$ & 0.000 & 14 & $0.615^{*}$ & 0.000 & 25 & $0.553^{*}$ & 0.000 \\
Behavior & 4 & $* 0.522$ & 0.000 & 15 & $0.772 *$ & 0.000 & 26 & $0.703^{*}$ & 0.000 \\
Modification & 5 & $* 0.491$ & 0.000 & 16 & $0.643 *$ & 0.000 & 27 & $0.644^{*}$ & 0.000 \\
Methods & 6 & $* 0.442$ & 0.000 & 17 & $* 0.555$ & 0.000 & 28 & $0.613^{*}$ & 0.000 \\
& 7 & $* 0.423$ & 0.000 & 18 & $0.654^{*}$ & 0.000 & 29 & $* 0.521$ & 0.000 \\
& 8 & $* 0.488$ & 0.000 & 19 & $0.554^{*}$ & 0.000 & 30 & $0.607^{*}$ & 0.000 \\
\hline
\end{tabular}




\begin{tabular}{cccccccccc}
\hline & 9 & $* 0.501$ & 0.000 & 20 & $0.774^{*}$ & 0.000 & 31 & $0.499^{*}$ & 0.000 \\
& 10 & $* 0.504$ & 0.000 & 21 & $0.666^{*}$ & 0.000 & 32 & $0.564^{*}$ & 0.000 \\
& 11 & $* 0.423$ & 0.000 & 22 & $0.584^{*}$ & 0.000 & & & \\
\hline Bullying & 1 & $0.604^{*}$ & 0.000 & 5 & $0.643^{*}$ & 0.000 & 9 & $0.493^{*}$ & 0.000 \\
Causes & 2 & $0.773 *$ & 0.000 & 6 & $* 0.624$ & 0.000 & 10 & $0.541^{*}$ & 0.000 \\
& 3 & $0.793^{*}$ & 0.000 & 7 & $0.833^{*}$ & 0.000 & 11 & $0.584^{*}$ & 0.000 \\
& 4 & $0.844^{*}$ & 0.000 & 8 & $0.544^{*}$ & 0.000 & 12 & $0.611^{*}$ & 0.000 \\
\hline
\end{tabular}

*Statistically Significant at $(\alpha=0.05)$

From Table 2, it is noticed that the items' correlation coefficients on the bullying behavior modification methods' scale ranged from $(0.423)$ to $(0.793)$, and all values were statistically significant at $\alpha=0.05$, which indicated a degree of discrimination validity for the items. It is also noticed that the items' correlation coefficients on the bullying causes' scale ranged from $(0.493)$ to $(0.844)$, and all values were statistically significant at $\alpha=0.05$, which indicated a degree of discrimination validity for the items.

Instruments' Reliability:

To verify the instruments' reliability, the instrument's reliability coefficients were calculated using the split-half method and calculating the internal consistency coefficients for items using the Cronbach Alpha, which measures the consistency of participants' responses to the items included in each instrument. Both instruments were applied on a pilot sample of (30) male and female teachers from the study population and other than its original sample, and Table 3 shows each of the internal consistency coefficients based on the Cronbach Alpha and reliability coefficients of half split for the items of both scales.

Table 3. Internal consistency coefficient Cronbach alpha and the split-half reliability coefficient for the two instruments

\begin{tabular}{ccccc}
\hline Items' No & Split-half & Cronbach Alpha & Instrument \\
\hline 32 & 0.927 & 0.944 & Bullying behavior modification methods & 1 \\
12 & 0.744 & 0.813 & Bullying causes & 2 \\
\hline
\end{tabular}

Table 3 indicates the reliability coefficients based on Cronbach alpha and half split methods for the bullying behavior modification methods' scale where the Cronbach alpha coefficient was (0.944) for the scale as a whole, and the split-half coefficient was (0.927). Table 3 also indicates the reliability coefficients based on Cronbach alpha and half split methods for the bullying causes' scale. Besides, the Cronbach alpha coefficient was (0.813) and the split-half coefficient was (0.744).

\section{Results of the Study}

First: Results related to the research first question: What are the causes of school bullying from teachers' perspective?

To answer this question, means and standard deviations were calculated together with estimation and ranks of the schools bullying modification score on the items as a whole from public school teachers' perspective in the university province directorate of education. Table 4 shows the results.

Table 4. Means and standard deviations of the schools bullying modification methods' score from the perspective of public-school teachers in the university province directorate of education

\begin{tabular}{llrrrr}
\hline No & \multicolumn{1}{c}{ Item } & Mean & SD & Rank & Level \\
\hline 30 & $\begin{array}{l}\text { The method of continuously encouraging the student to talk about his/her } \\
\text { suffering }\end{array}$ & 4.06 & 1.00 & 1 & High \\
24 & Social and logical persuasion method & 3.88 & 1.05 & 2 & High \\
25 & Using tolerance and withdrawing revenge from others & 3.85 & 1.05 & 3 & High \\
27 & Using the problem-solving method & 3.79 & 1.05 & 4 & High \\
26 & Method of training in self and social skills & 3.76 & 1.05 & 5 & High \\
11 & The method of self-affirmation and self-education training & 3.75 & 0.99 & 6 & High \\
13 & The method of firmness, application of the school system, and the issuance of & 3.73 & 0.98 & 7 & High \\
& deterrent penalties & & & \\
29 & The method of learning the skills of peaceful coexistence with others & 3.73 & 1.10 & 7 & High \\
\hline
\end{tabular}




\begin{tabular}{|c|c|c|c|c|c|}
\hline 1 & Using the verbal confrontation method & 3.70 & 0.96 & 8 & High \\
\hline 8 & Using the method of integration and interaction with others & 3.67 & 1.07 & 9 & High \\
\hline 31 & The method of encouraging students to take their rights through dialogue & 3.67 & 1.05 & 9 & High \\
\hline 7 & The method of directly correcting mistakes & 3.66 & 1.10 & 10 & Medium \\
\hline 6 & The method of psychological, school, and familial support & 3.63 & 1.10 & 11 & Medium \\
\hline 28 & The method of encouragement and self-confidence enhancement & 3.63 & 1.21 & 11 & Medium \\
\hline 2 & Method of effective participation of the parents of the bullies in finding solutions & 3.60 & 0.95 & 12 & Medium \\
\hline 5 & Behavioral contracting style and structured reinforcement method & 3.60 & 1.08 & 12 & Medium \\
\hline 3 & Periodic instruction method within the classroom & 3.58 & 0.94 & 13 & Medium \\
\hline 32 & Using the method of avoiding removal and isolation & 3.57 & 1.06 & 14 & Medium \\
\hline 10 & method of discussion and open dialogue & 3.56 & 1.08 & 15 & Medium \\
\hline 23 & $\begin{array}{l}\text { The method of teaching the bullying student to ask for help from the educational } \\
\text { counselor }\end{array}$ & 3.56 & 1.06 & 15 & Medium \\
\hline 9 & Using a preventive school program that reduces bullying behavior & 3.54 & 1.01 & 16 & Medium \\
\hline 19 & Using intermittent and continuous reinforcement schedules & 3.52 & 1.12 & 17 & Medium \\
\hline 4 & Using the method of praising the student in front of peers & 3.47 & 1.09 & 18 & Medium \\
\hline 14 & The method of school interest in the bullying student and his sense of his value & 3.44 & 1.05 & 19 & Medium \\
\hline 18 & Using a calming and self-reassuring technique & 3.44 & 1.09 & 19 & Medium \\
\hline 20 & Counseling and advising method & 3.44 & 1.07 & 19 & Medium \\
\hline 22 & $\begin{array}{l}\text { The method of stopping the irrational thoughts of the bullying student } \\
\text { immediately }\end{array}$ & 3.38 & 1.05 & 20 & Medium \\
\hline 17 & The method of teaching the bullying student to accept criticism from others & 3.34 & 1.09 & 21 & Medium \\
\hline 21 & A method based on understanding and responding to the needs of peers & 3.33 & 1.07 & 22 & Medium \\
\hline 15 & Using the instant reward method & 3.29 & 1.09 & 23 & Medium \\
\hline 16 & $\begin{array}{l}\text { The method of teaching the bullying student the sense of psychological security } \\
\text { skills }\end{array}$ & 3.25 & 1.10 & 24 & Medium \\
\hline \multirow[t]{2}{*}{12} & The method of training the bullying student to take personal responsibility & 3.23 & 1.12 & 25 & Medium \\
\hline & Total & 3.58 & 0.91 & & Medium \\
\hline
\end{tabular}

Table 4 shows that the means of the score of the school bullying behavior modification methods' scale from teachers' perspective in the university province directorate of education schools ranged from (3.23) to (4.06) at a level from medium to high of estimation score on the items, for the instrument as a whole, the mean was (3.58) and the standard deviation reached (0.91) at a medium level.

In the first rank came the item number (30)," The method of continuously encouraging the student to talk about his/her suffering" at a high level with a mean of (4.06), followed by the item number (24)" Social and logical persuasion method" with a mean of (3.88) at a high level, too. Finally came item number (12), "The method of training the bullying student to take personal responsibility," with a mean of (3.23) at medium level.

Second: Results related to the research second question: What are school bullying modification methods from teachers' perspective?

To answer this question, means and standard deviations were calculated, estimated, and ranks of the school bullying cause' score on the items as a whole from public schools' teachers' perspective in the university province directorate of education. Table 5 shows the results.

Table 5. Means and standard deviations of the bullying causes' score on the items as a whole from public schools' teachers in the university province directorate of education

\begin{tabular}{llrrrr}
\hline No & Item & Mean & SD & Rank & Level \\
\hline 10 & $\begin{array}{l}\text { The psychological and emotional state of the bullying student has a role in } \\
\text { increasing this behavior }\end{array}$ & 3.68 & 0.98 & 1 & High \\
8 & $\begin{array}{l}\text { Media such as television and the Internet have a role in increasing students' } \\
\text { bullying behavior }\end{array}$ & 3.65 & 1.06 & 2 & Medium \\
\hline
\end{tabular}


$5 \quad$ School can affect students' behavior

6 Bullying of some students arises from the lack of clarity of school regulations and instructions

3 The student's upbringing style has a role in the emergence of this behavior

1 Family breakdown has a great role in increasing the aggressive behavior of a bullying student

2 Parents' educational and cultural level has a role in students' bullying

7 Bullying of some students arises from a weak relationship between the school and the family

11 The student bullying because he/she was a victim of bullying before

4 The economic situation is one of the factors that push the student to bully

12 The negative influence of peers plays a role in the emergence of this behavior

9 Bullying student has a strong personality

\begin{tabular}{llll}
3.56 & 1.13 & 3 & Medium \\
3.55 & 0.97 & 4 & Medium \\
3.54 & 1.08 & 5 & Medium \\
3.53 & 1.06 & 6 & Medium \\
3.48 & 1.07 & 7 & Medium \\
3.43 & 1.07 & 8 & Medium \\
3.42 & 1.08 & 9 & Medium \\
3.38 & 1.16 & 10 & Medium \\
3.36 & 1.05 & 11 & Medium \\
3.26 & 1.09 & 12 & Medium \\
3.49 & 0.91 & & Medium \\
\hline
\end{tabular}

Table 5 shows that means of the bullying causes scale from public school teachers' perspective in the university province directorate of education ranged between (3.26) and (3.68) for the items from high to medium level, while the total mean for the scale as a whole was (3.49) with a standard deviation of (0.91) at a medium level. The 10th item, "The psychological and emotional state of the bullying student, has a role in increasing this behavior, "first with a mean of (3.68) a high level. The 8th item followed this, "Media such as television and the Internet have a role in increasing students' bullying behavior," which emerged with a mean of (3.65) at a medium level. And finally came the 9th item, "Bullying student has a strong personality," with a mean of (3.26) at a medium level.

Third: Results related to the research third question: Are there statistically significant differences at the value $(\alpha=0.05)$ from teachers' perspectives about bullying causes and its modification methods based on the variables of gender, educational qualification, and years of experience?

To answer this question, means and standard deviations for the participants' responses on the bullying modification methods' scale and the bullying causes' scale were calculated based on the study variables. To explain the statistical differences between the means, the t-test of independent samples was used with the gender, educational qualification variables, and the One-Way ANOVA was used with the experience variable as shown in the tables below.

\section{First: Gender}

Table 6. Means, standard deviations, and the t-test for the effect of gender on the causes of bullying and its modification methods from public schools teachers' perspective

\begin{tabular}{cccccccc}
\hline Scale & Gender & Number & Mean & SD & t-value & Freedom scores & Sig \\
\hline \multirow{2}{*}{ Bullying modification methods } & Male & 93 & 3.30 & 0.93 & \multirow{2}{*}{3.741} & & 287 \\
& Female & 196 & 3.72 & 0.87 & & & 0.000 \\
Bullying causes & Male & 93 & 3.23 & 0.89 & \multirow{2}{*}{3.304} & 287 & 0.001 \\
& Female & 196 & 3.61 & 0.90 & & & \\
\hline
\end{tabular}

Table 6 indicates statistically significant differences at the value $(\alpha=0.05)$ between participants estimations' means on the scale of bullying behavior modification methods as a whole from public schools teachers' perspective in the university province directorate of education. Those are attributed to the variable of gender in favor of female participants where the value of the t-test was (3.741) on the scale as a whole with a significance of (0.000), and this is a statistically significant value at $(\alpha=0.05)$.

Table 6 also indicates statistically significant differences at the value $(\alpha=0.05)$ between participants estimations' means on the scale of bullying causes as a whole from public school teachers' perspective in the university province directorate of education that is attributed to the variable of gender in favor of female participants where the value of the t-test was (3.304) on the scale as a whole with a significance of $(0.001)$ and this is a statistically significant value at $(\alpha=0.05)$. 


\section{Second: Educational Qualification}

Table 7. Means, standard deviations, and the t-test for the effect of the educational qualification on the causes of bullying and its modification methods from public school teachers' perspective

\begin{tabular}{|c|c|c|c|c|c|c|c|c|}
\hline & Scale & Qualification & Number & Mean & SD & t-value & Freedom scores & Sig \\
\hline \multirow{2}{*}{1} & \multirow{2}{*}{ Bullying modification methods } & Bachelor & 175 & 3.19 & 0.93 & \multirow{2}{*}{10.563} & \multirow{2}{*}{287} & \multirow{2}{*}{0.000} \\
\hline & & Higher Studies & 114 & 4.80 & 0.87 & & & \\
\hline \multirow{2}{*}{2} & \multirow{2}{*}{ Bullying causes } & Bachelor & 175 & 3.10 & 0.89 & \multirow{2}{*}{10.257} & \multirow{2}{*}{287} & \multirow{2}{*}{0.000} \\
\hline & & Higher Studies & 114 & 4.07 & 0.90 & & & \\
\hline
\end{tabular}

Table 7 indicates statistically significant differences at the value $(\alpha=0.05)$ between participants estimations' means on the scale of bullying behavior modification methods as a whole from public school teachers' perspective in the university province directorate of education that is attributed to the variable of educational qualification in favor of higher studies where the value of the t-test was (10.563) on the scale as a whole with a significance of (0.000), and this is a statistically significant value at $(\alpha=0.05)$.

Table 7 also indicates statistically significant differences at the value $(\alpha=0.05)$ between participants estimations' means on the scale of bullying causes as a whole from public school teachers' perspective in the university province directorate of education that is attributed to the variable of educational qualification in favor of higher studies where the value of the t-test was (10.257) on the scale as a whole with a significance of $(0.000)$, and this is a statistically significant value at $(\alpha=0.05)$.

\section{Third: Experience Years}

Table 8. Means and standard deviations of the effect of experience on the causes of bullying and its modification methods from public school teachers' perspective

\begin{tabular}{ccccc}
\hline Scale & Experience & Number & Mean & SD \\
\hline \multirow{3}{*}{$\begin{array}{c}\text { Bullying modification } \\
\text { methods }\end{array}$} & Less than 5 years & 59 & 2.88 & 1.09 \\
& 5 to less than 10 years & 79 & 3.72 & 0.84 \\
& 10 years and above & 151 & 3.78 & 0.74 \\
Bullying causes & Total & 289 & 3.58 & 0.91 \\
\hline & Less than 5 years & 59 & 2.79 & 1.08 \\
& 5 to less than 10 years & 79 & 3.65 & 0.84 \\
& 10 years and above & 151 & 3.66 & 0.74 \\
\hline
\end{tabular}

Table 8 indicates apparent differences between the means on the bullying behavior modification methods' scale from public school teachers' perspective in the university province directorate of education based on the variable of experience on each dimension and the tool as a whole.

To determine the statistical differences between the means, the One-Way ANOVA was used to identify the extent of the existence of statistically significant differences in participants' responses as shown in Table 9 below:

Table 9. One Way ANOVA for the effect of experience on the causes of bullying and its modification methods from public school teachers' perspective

\begin{tabular}{ccccccc}
\hline Scale & Variance source & Squares' sum & Freedom scores & Squares' mean & F Value & Sig \\
\hline \multirow{2}{*}{ Bullying modification } & Within groups & 36.448 & 2 & 18.224 & 25.537 & $* .000$ \\
methods & Among groups & 204.102 & 286 & .714 & & \\
& Total & 240.550 & 288 & & & \\
& Within groups & 35.480 & 2 & 17.740 & 24.754 & $* .000$ \\
Bullying causes & Among groups & 204.960 & 286 & .717 & & \\
& Total & 240.440 & 288 & & & \\
\hline
\end{tabular}

*Statistically Significant at ( $\alpha=0.05)$

Table 9 indicates statistically significant differences at the $(\alpha=0.05)$ value between the participants' estimations' means on the scale of bullying behavior modification methods that are attributed to the variable of experience 
with an $\mathrm{F}$ value of (24.754) on the scale as a whole and a significance of $(0.000)$ which is a statistically significant one at the $(\alpha=0.05)$ value.

The table also indicates statically significant differences at the $(\alpha=0.05)$ value between the participants' estimations' means on the scale of bullying causes that are attributed to the variable of experience with an $\mathrm{F}$ value of (25.537) on the scale as a whole and a significance of $(0.000)$ which is a statistically significant one at the $(\alpha=0.05)$ value.

To determine the statistically significant differences' locations based on the experience variable, post comparisons based on the Scheffe test were used as shown in Table 10 below:

Table 10. Post comparisons results of the Scheffe test for the experience variable

\begin{tabular}{cccccc}
\hline Scale & Experience years & Mean & Less than 5 years & 5 to less than 10 years & 10 years and above \\
\hline Bullying & Less than 5 years & 2.88 & - & $* .000$ & $* .000$ \\
modification & 5 to less than 10 years & 3.72 & - & & .875 \\
methods & 10 years and above & 3.78 & & $* .000$ & - \\
& Less than 5 years & 2.79 & - & - & .000 \\
Bullying & 5 to less than 10 years & 3.65 & & & - \\
causes & 10 years and above & 3.66 & & & - \\
\end{tabular}

*Statistically Significant at $(\alpha=0.05)$

Table 10 indicates statistically significant differences at $(\alpha=0.05)$ between participants estimations' means on the scale of bullying behavior modification methods attributed to the experience variable, and these differences were between those with less than 5 years, those with 5 to less than 10 years, and those with 10 years and above experiences. The differences were in favor of the experiences of 10 years and above.

The table above indicates statistically significant differences at $(\alpha=0.05)$ between participants' estimations' means on the scale of bullying causes attributed to the experience variable. These differences were between those with less than 5 years, those with 5 to less than 10 years, and those with 10 years and above experiences. The differences were in favor of the experiences of 10 years and above.

\section{Discussion of the Results}

The study is to recognize school bullying among teenagers. Reasons and modification ways from the side of the teachers. The first questionnaire results showed the statistical average on the bullying modification ways, and its reasons were in an average degree. The second Questionnaire showed statistical differences in bullying for females.

The third Questionnaire showed differences for the scientific qualification of the higher education students and experience years for more than 10 years.

The current study is distinguished from the others in that it studied bullying ways and reasons and recognized the bullying reasons in targeted society. Also, we found that the current study results are adapted with the study of (Al Omary, 2019). from the bullying reasons where the current study result was high and average in some articles, this adaptation is because of the similarity in the study communities' private environment. The study results agreed with the study of (Lisa DeLuca, Analaura, \& Ersila, 2019). Which showed the qualification of teachers to minimize school bullying. This agreement goes back to the teachers' availability of awareness and educational sense to decrease and minimize the students' bullying.

Another study result agreed with (ken \& right, 2018). which indicates the availability of phenomena among the students, and the current study ensures that the bullying phenomenon is common among the school students. Goal (2018) study meant recognizing the ways and reasons of bullying showed that self and family reasons of bullying showed self and family reasons linked to the student surrounding community environment. This agreement refers to the community similarity where the students live because they have common interests, habits, and traditions. It agreed with Belmndi's (2017) study, which indicates giving the students independence to minimize bullying. This agreement refers to the programs and courses of awareness increase and guidance for the students to minimize bullying.

Al-Gathani (2015) study indicates the availability of bullying understanding in its shapes and effects. The current study agrees with this study that teachers have an awareness degree of bullying reasons because of teachers' experience in dealing with the students. It agreed with Ruyad's (2017) study, which indicates the bullying availability in private and government schools. This agreement comes because the study comes from the same 
environment where the study happened. It agreed with Salih et al. (2017), which meant recognizing the bullying behavior from the teacher's opinion who ensured the availability of bullying phenomena among students. This study result was disapproved by Abdulrahim (2017), which showed that teachers and principals have a week ability to face bullying, which goes back to the contradiction because they don't know the danger of bullying among students or reasons linked to the surrounding environment and the awareness and cultural degree among the community members. We noticed that the study results agreed with previous studies' results, except the study of Abdul Rahim (2017), which indicates the study result accuracy. Also, it is distinguished by its role to study the result and ways of modification to increase the knowledge of the danger of the phenomena in the communities.

\section{Conclusions}

1-The reasons and ways of bullying came in average degree among the study group members.

2-Reasons and ways of school bullying were from the side of females.

3-School bullying phenomena are still available in the school environment.

4-The years of experience and scientific qualification for the years help in minimizing that bullying phenomenon.

\section{Recommendations}

1-Working on increasing the training for teachers and principals in a way to deal with school bullying phenomena.

2-Increasing the guidance programs among students.

3-Preparing school curriculum for the students to be taught in all school stages.

4-Preparing sports gym including all the sports activities in the school.

\section{References}

Abderrahim, M. (2017). The Role of Technical Secondary Schools' Principals in Alsharqeyyah Governorate from Teachers' Perspective. Arabic Studies in Education and Psychology, (85). Published by Arab Educators Association.

Abu Addayyar, M. (2012). Psychology of Bullying Between Theory and Therapy (2nd ed.). Dar Alkitab Alhadith (New Book Office).

Abu Ghazal, M. (2009). Bullying and its Relationship to Loneliness and Social Support. The Jordanian Journal of Educational Sciences, 2(5), 80-113.

Albahhas, A. (2012). Psychological Safety Among Bullies' Victims and their Peers Victims of Schools Bullying: Psychometric-Clinical Study. Journal of Education Faculty, 92(11).

Alo'mari, S. (2019). Realty of School Bullying Problem Among Elementary Stage Students, Prevention and Therapy. Journal of Educational and Psychological Sciences, 3(3). KSA.

Alqahtani, N. (2015). The extent of Awareness Towards Bullying Among Elementary Stage Female Teachers and Realty of Procedures Followed to Prevent it in Public Schools in Riyadh City/ KSA from their Perspective. Arabic Studies in Education and Psychology. King Sound.

Al-Raqqad, H., Al-Bourini, E., Al Talahin, F., \& Aranki, R. (2017). The Impact of School Bullying on Students' Academic Achievement from Teachers Point of View. International Education Studies, 10(6), 44-50. https://doi.org/10.5539/ies.v10n6p44

Alsobhiyeen, A., \& Alqdah, M. (2013). Bullying Behavior Among Children and Adolescents (its Concept, Causes, and Therapy) (1st ed.). Studies and Research Center, Nayif University for Security Sciences. Riyadh. KSA.

Alsoufi, O., \& Almaliki, F. (2012). Bullying Among Children and its Relationship With Parental Treatment Methods. Journal of Educational and Psychological Research, (35), 146-188.

Alyafi'i, A. (2018) School Bullying at Schools. Security and Social Education Journal, 47(574). Retrieved from https://www.moi.gov.ae/DataFolder/2018magazine999/aroct2018.pdf

Bahshawi, A., \& Hassan, R. (2015). Schools Bullying and its Relationship with Achievement Motivation Among Intermediate Stage Students. Port Said University, Faculty of Education Journal, (17).

Bidwell, N. (1997). The Nature and Prevalence of Bullying in Elementary Schools (pp. 97-106). A summary of Master's Thesis from http://www.Ssta.caimprovementHTML.Research-school 
Bilmahi, D. (2017). Methods of Mitigating Teens' Bullying from Teachers and Educational Supervisors. Unpublished M.A Thesis. Molai Al-Tahir Sa'idah University.

Bu-Nab, A. (2017). School Bullying and its Relationship with Social Skills Among Intermediate Second-and Third-Years Students. Unpublished M.A Thesis. Mohammad Bu-Dhiaf University' Algeria.

Gholi, H., \& Al-I'kili, J. (2018). Reasons of School Bullying Behavior Among (1st). Intermediate Grade Students and its Modification Methods from Male and Female Teachers. Females Faculty of Education Journal, 29(3).

Ken, R. (2018). Exploring the gaps between teachers' beliefs about bullying and research-based knowledge. Psychology, 6, 165-175. https://doi.org/10.1080/21683603.2017.1314835

Lisa, D., Annalaura, N., \& Ersilia, M. (2019). The Teacher's Role in Preventing Bullying. Italy.

Sahloul, M., Alhaddad, B., Hamdan, H., Abu Shamalah, A., \& Abu A'sir, M. (2018). The Reality of Bullying Phenomenon Among Secondary Stage Students in Khan Younis Governorate and the Methods to Confront it. Scientific Research Center. Ministry of Education, Khan Younis Directorate of Education. Deanship of Scientific Research, (58).

Salehi, S., Patal, A., Taghavi, M., \& Porvary, M. (2016). Primary School Teachers and Parents Perception of Peer Bullying Among Children in Iran: A Qualitative Study. Iran J Psychiatry Behav Sci., 10(3). https://doi.org/10.17795/ijpbs-1865

Smith, B. (2000). Bullying and harassment in school and rights of children. Journal of children \& society, 14(4), 294-303. https://doi.org/10.1111/j.1099-0860.2000.tb00184.x

Wolke, D., Wood S., Stanford, K., \& Schulz's, H. (2001). Bullying and Victimization of Primary School Children in England and German: Prevalence and School factors. British Journal of Psychology, 92, 673-696. https://doi.org/10.1348/000712601162419

\section{Copyrights}

Copyright for this article is retained by the author(s), with first publication rights granted to the journal.

This is an open-access article distributed under the terms and conditions of the Creative Commons Attribution license (http://creativecommons.org/licenses/by/4.0/). 